\title{
O partido do Rio Grande: redes de relações, mediação e Revolução de 1930
}

Cássia Daiane Macedo da Silveira*

Resumo: $\mathrm{O}$ presente artigo pretende analisar algumas formas de participação política nas articulaçóes que conformaram a Aliança Liberal. O centro da análise, contudo, não são os agentes clássicos da história política, como políticos de carreira e outros indivíduos vinculados à política partidária, mas os intelectuais e, paralelamente, os empresários. Entende-se que esses agentes poderiam ter um papel de mediação entre os políticos e setores proeminentes da sociedade, auxiliando na conformaçáo de um ambiente propício ao sucesso de seus projetos. Palavras-chave: Revolução de 1930. Intelectuais. Mediadores.

\section{Introduçáo}

O estudo das relaçôes entre os intelectuais e a política já é bastante reconhecido. Para Jean-François Sirinelli (2003), o estudo de suas ideias, de seus modos de organização e de suas influências é capaz de trazer valiosas informaçóes a respeito da história política do local onde atuam, ainda que esta seja sempre uma história parcial. Antes dele, Pierre Bourdieu (2005) e seus adeptos no Brasil, como Sérgio Miceli (2001), já haviam afirmado a estreita vinculação entre aquilo que fazem os intelectuais e aquilo que fazem os políticos. Muitas vezes ocupando os mesmos espaços, em outras tantas compartilhando

\footnotetext{
* Professora Adjunta da Universidade Federal do Pampa - UNIPAMPA. Doutora em História Social pela Universidade Estadual de Campinas - UNICAMP. E-mail: cassiamsilveira@gmail.com.
} 
as mesmas salas de aula ou até mesmo laços familiares, as lealdades constituídas entre intelectuais e homens da política, entre a sua produção e o poder, apesar de bastante conhecidas, nunca deixam de ser relevantes, atraindo sempre novos estudos.

O objetivo deste artigo, nesse sentido, é discutir o papel e a participação dos intelectuais na Revolução de 1930, mais precisamente nas alianças que antecederam tal evento político, mas atentando para outros desenvolvimentos de sua atuação, levando em consideração, por exemplo, os vínculos variados que mantinham com indivíduos ligados a diversos setores das elites, fossem elas econômicas ou políticas. Assim, o que se pretende é compreender alguns aspectos do papel de "mediação" que certos intelectuais desempenharam, que incluía tanto a participação em círculos de elite, favorecendo inúmeros arranjos políticos, quanto em seus empreendimentos de propaganda do estado sulino, por meio, no caso aqui estudado, da divulgação de sua literatura. Em geral difundido em publicações locais, como a Revista do Globo, o que se argumenta aqui é que, devido à ação de alguns intelectuais, designados neste artigo como "mediadores", tal discurso, de certa forma, difundiu-se por outras regióes do Brasil, particularmente na Capital Federal, espaço político crucial para a articulação de apoio à Aliança Liberal. Além disso, tais agentes também tiveram intensa atuação social, frequentando espaços tipicamente de elite, como o Rotary e o Jockey Club, que propiciaram diversos tipos de articulação política. O carioca Rodrigo Otávio Filho e o gaúcho Felipe d'Oliveira estarão no centro da análise.

A literatura histórica tem se valido da ideia de "mediação" atribuindo a certos indivíduos, instituiçóes ou grupos a capacidade ou a faculdade de possibilitar a relação entre instâncias distintas da sociedade, notadamente, entre indivíduos, instituições ou grupos de ação restrita e local e indivíduos, instituições ou grupos de ação mais ampla, em certos casos nacional, ou mesmo entre grupos políticos de atuação regionalizada e o Estado. Assim, diferentes comunidades de uma mesma sociedade estariam interligadas por redes de relaçóes entre grupos de pessoas, que também conectariam as instâncias locais de atuação às instituiçóes nacionais. Os "mediadores" entre essas instâncias seriam dotados, sobretudo, de um vasto capital de relaçóes sociais que acionariam com objetivos específicos em certos 
momentos-chave, articulando demandas de comunidades localizadas com sistemas políticos mais gerais, de caráter estrutural. Dessa atuação adviriam benefícios que poderiam ser de natureza material ou simbólica, tanto para as duas classes de grupos envolvidos na mediação quanto para o mediador em si (WOLF, 2003; LEVI, 2000).

No caso aqui estudado, a ideia de que haveria certos indivíduos atuando socialmente na posição de mediadores entre grupos ou instâncias sociais distintos adquire novo sentido, uma vez que tanto Felipe d'Oliveira quanto Rodrigo Otavio Filho apareciam publicamente na condição de intelectuais. Nesse sentido, compreender essa faceta de sua atuação implica igualmente elucidar alguns aspectos ainda obscuros da relação entre as ideias políticas, os indivíduos que as carregam e a organização da política-partidária concreta, bem como a possibilidade de compreender melhor os diversos modos de atuação política dos intelectuais.

\section{Intelectuais gaúchos no início do século $\mathrm{XX}$ : tentativa e fracasso de transformaçáo de uma imagem}

"O Rio Grande, no Brasil, para os brasileiros, é uma espécie de Macedônia de atraso e de barbarismo” (MAYA, 1900, p. 93 apud MURARI, 2010, p. 175) - esse era o ponto de vista, no ano de 1900, do que o Rio Grande do Sul representava para o restante do país, exprimido por um dos principais críticos e literatos do estado: Alcides Maya. No ambiente literário do Rio Grande do Sul da primeira década do século XX, Maya constituía-se em uma referência aos escritores mais jovens, que frequentemente lhe dedicavam livros e poesias. Figurava, ao lado de Zeferino Brazil e Arthur Pinto da Rocha, entre os grandes do cenário intelectual regional. Segundo Luciana Murari, Maya, com a sentença citada, criticava o modo pelo qual os demais estados brasileiros costumavam perceber o Rio Grande do Sul, como se, tendo se dedicado sobretudo à guerra, não tivesse guardado lugar para dedicar-se à literatura. $\mathrm{O}$ escritor, assim, proporia que 
[...] uma vez superada a fase bélica, o estado poderia, enfim, dedicar-se mais intensamente às produçóes do espírito, convertendo este passado em tema literário, ou seja, em componente histórico fundamental para a construção do patrimônio identitário do estado, negando, entretanto, a validade da guerra como soluçáo política do seu tempo (MURARI, 2010, p. 175).

Alcides Maya não se consagrou unicamente devido à sua atuação como literato ou como crítico, mas também em decorrência da militância que levava adiante em torno de projetos modernizadores e que foi vista como contraditória em relação à sua literatura. Para Murari,

[...] tem sido observada uma aparente incoerência entre a militância jornalística do escritor, voltada para a formulação de projetos para o futuro a partir do aprimoramento das instituiçóes políticas e do incentivo às forças produtivas, e uma literatura que tem como temas privilegiados a guerra, a morte, a decadência e a inadaptação (MURARI, 2008, p. 151).

Alcides Maya, apesar de uma literatura desencantada, tinha por projeto a elevaçáo do Rio Grande do Sul por meio de sua literatura. Ele idealizava um lugar grandioso para seu estado natal dentro da nacionalidade brasileira. Esse seu empreendimento esteve presente, por exemplo, quando da visita do escritor maranhense Henrique Maximiliano Coelho Netto ao Rio Grande do Sul, no ano de 1906, numa época em que eram comuns as conferências literárias como divertimento frívolo para as elites (BROCA, 1975, p. 137). Segundo uma das versóes para a história, a vinda de Coelho Netto, um dos principais romancistas brasileiros daquele tempo, teria sido articulada entre Alcides Maya e Carlos "Cavaco" (militante operário que também escrevia literatura e publicava textos em jornais) com o intuito declarado de um ciclo de conferências (O DIA, 1906, p. 1). No convite estava implícito o desejo de apresentar a Coelho Netto, escritor que, na época, gozava de intenso reconhecimento público, uma imagem distinta do gaúcho daquela pela qual, imaginava-se, o estado era visto pelo resto do país. Em Através da Imprensa, coletânea de artigos publicados em jornais, editada em 1900, Alcides Maya 
esboça seu pensamento sobre essa questão, ao propor que a integração gaúcha na unidade cultural brasileira estava atrelada a "[...] uma mudança radical da imagem que o Brasil possuía do estado, e de sua própria auto-imagem, ambas associadas ao belicismo que definiu sua história" (MURARI, 2008, p. 7). De certa forma, a ideia de chamar o reconhecido escritor maranhense derivava desse pensamento, uma vez que o próprio Coelho Netto, segundo Maya, chegava a pensar na hipótese de escrever sob inspiração dos pampas e coxilhas.

Contudo, o projeto de envolver Coelho Netto no empreendimento de integrar o Rio Grande do Sul com a nacionalidade brasileira de uma forma positivada encontrava, naquele momento, uma série de barreiras, bastante conhecidas por Alcides Maya. Em carta a Carlos Cavaco, Maya manifesta sua preocupação:

A sua ideia de conferências, aí, pelos artistas e literatos de cá
[do Rio de Janeiro, onde Alcides Maya vivia na época], foi,
portanto, muito boa. Mas, note a responsabilidade! Coelho
Netto tem sido recebido como um príncipe em todos os
Estados do Norte. Já foi até o Amazonas e sempre e por toda
a parte, governos, jornalistas e povo o apoteosaram, pode-se
dizer. Imagine o desastre de uma recepção vulgar no Rio
Grande, dados os infelizes antagonismos de pessoa e de ideia
que extremam os melhores elementos da intelectualidade
gaúcha! (O DIA, 1906, p. 1)

De fato, a leitura de Alcides Maya sobre o momento que o Rio Grande do Sul vivenciava quando da vinda de Coelho Netto, em 1906, talvez faça sentido. Por mais que tenha posto em prática sua ideia de fazer o maranhense conhecer e apreciar o Rio Grande e que Coelho Netto efetivamente tenha conhecido os recantos mais profundos do estado, naquele momento, o projeto de transformaçáo da imagem do Rio Grande do Sul perante o Brasil talvez ainda náo encontrasse $\mathrm{o}$ ambiente adequado para ser bem sucedido. A ausência de uma editora coesa dotada de projeto editorial com centralidade nos autores gaúchos e capaz de publicá-los, dando vazáo a essa ideia, bem como a falta de coesão política das elites rio-grandenses naquele momento talvez possam explicar o "fracasso" dessa ideia naquele 
contexto. Esse quadro altera-se já na década de 1920, quando as oligarquias gaúchas encontram maior unidade e buscam objetivos políticos comuns, e quando a Livraria do Globo inicia uma etapa de expansão, tornando-se a mais importante casa editora do sul do Brasil. ${ }^{1}$ Aliás, o complexo entrelaçamento entre intelectuais e políticos durante a Primeira República pode ser muito bem ilustrado pelo caso dessa grande editora, que foi a Editora do Globo, do Rio Grande do Sul.

Criada em fins do século XIX, a Livraria do Globo só começou a investir em ediçóes a partir da década de 1920, sistematizando definitivamente a prática em 1928 (HALLEWELL, 1985, p. 311). As relaçóes entre os intelectuais que faziam parte do chamado "grupo da Globo" e a política partidária, particularmente com os eventos que desembocaram na Revolução de 1930, não são nenhuma novidade. Argumenta-se, inclusive, que o próprio Getúlio Vargas teria financiado a Revista do Globo quando era presidente do estado (VERGARA, 1960, p. 18). Para bem compreendermos essas relações, contudo, é necessário retomar os idos da década de 1920, quando um clima de grande otimismo tomou conta da intelectualidade rio-grandense. Ao contrário do que ocorria no começo do século XX, quando predominava uma escrita pessimista e "cansada", marcada, por exemplo, pela literatura de Alcides Maya, a partir da década de 1920, há uma renovação no meio intelectual no Rio Grande do Sul, que agora busca constituir uma escrita sobre o estado capaz de valorizar uma série de qualidades ligadas ao gaúcho - vinculadas de uma forma ou de outra ao telurismo, à sua ligação com a natureza, mas também à virilidade do homem gaúcho (a força e a coragem, por exemplo) - e desvalorizar o seu contrário (a fraqueza, a covardia).

Os intelectuais gaúchos vivenciaram, no decurso da década de 1920, um período de grande efervescência criativa, na qual vigorava peculiar otimismo com relação ao papel que o Rio Grande do Sul tinha a desempenhar perante a nacionalidade brasileira. Em termos literários, encontramos, nesse período, uma transformação no conteúdo das narrativas de cunho regionalista, embora pouco se alterasse sua forma: os escritores do Rio Grande do Sul, já nos anos 1920, retomam o mito positivado do gaúcho-herói. Para Ligia Chiappini Moraes Leite, nesse momento, crucial para o desenvolvimento das alianças políticas que buscavam desarticular os pactos entre Minas 
Gerais e São Paulo, efetiva-se um “compromisso ideológico” entre o discurso literário e os anseios políticos das oligarquias gaúchas (LEITE, 1978, p. 159). Assim, os intelectuais da nova geração, particularmente aqueles vinculados ao grupo da Livraria do Globo, e mesmo alguns de geraçóes mais antigas, como é o caso de Alcides Maya, passaram a atuar em prol da ideia comum de "Rio-grandização do Brasil”. Segundo Luciana Murari (2010, p. 181), o escritor Alcides Maya, em texto de 1913, já falava nesse tema e atribuía a ideia ao político liberal Gaspar Silveira Martins, ainda no Império, e talvez seja a partir dessa chave de análise que podemos entender o investimento que o escritor gaúcho fez sobre Coelho Netto em 1906.

Muito embora essa ideia não fosse nova, nem tivesse sido uma criação da década de 1920, ela foi reapropriada em novo contexto, dessa vez mais favorável ao sucesso. Num momento político conturbado, de intensas disputas intra-oligárquicas, consolidou-se na literatura local a ideia de que o gaúcho, ser saudável, honrado, heroico, valente, viril, entre outros adjetivos de positivação, e apenas ele, seria capaz de moralizar a política nacional. Em um sistema político "viciado", como julgava-se que era o sistema político da Primeira República, somente as qualidades naturais do gaúcho poderiam regenerar o país. $\mathrm{O}$ mito do gaúcho-herói, que habitou os textos literários de boa parte da intelectualidade rio-grandense da década de 1920, nos meses que antecedem o pleito de 1929 e, logo após, que antecedem a Revolução de 1930, expande-se também para os discursos políticos (LEITE, 1978, p. 164).

\section{Meu partido é o Rio Grande ou a Rio-Grandizaçáo ganha o Brasil}

No ano de 1928, Rodrigo Otavio Filho escrevia sobre a nova literatura nascente no Rio Grande do Sul. Filho de Rodrigo Otavio Landgaard Meneses, Rodrigo Otavio era poeta e advogado no Rio de Janeiro e tinha grande circulação nos meios intelectuais e políticos da Capital Federal. Suas reflexôes sobre a literatura gaúcha do final da década de 1920 eram fruto de uma visita que fizera ao estado na qual fora recepcionado por alguns dos indivíduos do grupo da Livraria do 
Globo. Rodrigo Otavio conta para nós que começou a leitura de Gado Chucro, de Vargas Netto, já no navio de volta para o Rio de Janeiro:

Recebera-o a bordo, momentos antes da partida, das mãos do próprio poeta. Mansueto Bernardi, o cantor meigo e sereno, e ao mesmo tempo inspirador e diretor daquela oficina inteligente que é a Livraria do Globo, apressara a composição do último livro de Vargas Netto, para que eu tivesse a alegria de trazê-lo, como último regalo da cativante amabilidade gaúcha (FILHO, 1928, p. 2, grifos do autor).

O relato de Rodrigo Otavio não se restringia, no entanto, aos caprichos literários do autor gaúcho, mas também a todo o ambiente intelectual constituído na capital gaúcha, onde convivera com o autor. Ele conta para nós que foi apresentado a Vargas Netto por meio de um amigo em comum quando circulava pela Rua da Praia e, já no dia seguinte, frequentava a casa do poeta, juntamente com Paulo Arinos (na época, o pseudônimo de Moysés Vellinho), a fim de discutir literatura enquanto começava "[...] a rodar a cuia do mate chimarrão". Rodrigo Otavio fez questão de afirmar que levou consigo "[...] a cuia e a bomba que foram os meus primeiros elementos de contato com a gente inteligente do Rio Grande" (FILHO, 1928, p. 3). A cuia com que Rodrigo Otavio fora presenteado náo era uma cuia qualquer; contava com o trabalho artesanal de Adalberto Aranha, que havia gravado,

[...] à ponta de canivete, um trecho de estância gaúcha, uns versos improvisados de Vargas Netto:

Por causa de uma chinoca

Com boca de ariticum

Eu sou rapaz de passear

Uma semana em jejum... (FILHO, 1928, p. 3, grifos do autor)

Todos esses detalhes enfocados por Rodrigo Otavio em seu texto não parecem simplesmente tratar da literatura gaúcha daquele período, mas também da sua gente. Os traços culturais típicos do Rio Grande do Sul, como a cuia e o chimarrão, estavam intrincados na 
literatura do estado, assim como os versos de Vargas Netto gravados com canivete na cuia que Rodrigo Otavio levava ao Rio de Janeiro. Náo se tratava, assim, de simplesmente divulgar a nova literatura que surgia mais ao sul do Brasil, mas de associar essa literatura a todo um contexto cultural típico que se pretendia exaltar.

Igualmente, esse contexto cultural regional não era apresentado como meramente rio-grandense, mas como brasileiro, integrando perfeitamente o Rio Grande do Sul na nacionalidade. Vargas Netto escrevia sobre a querência e o pago, mas nem por isso deixava de ser um poeta representativo da nação:

Vargas Netto é um poeta regional. Não por escola literária, mas por bairrismo, por amor aos pagos, porque vive na cidade pensando as querências... E o bairrismo é uma necessidade, principalmente para o brasileiro, cujo espírito dispersivo e espantado, facilmente se impressiona com tudo que vem de terra estranha. É por isso que sempre queremos bem aos poetas do Brasil brasileiro, como este Vargas Netto, que conta o Rio Grande de todas as horas e de todos os tempos, nos seus livros publicados: Joá, Tropilha Crioula e Gado Chucro (FILHO, 1928, p. 5, grifos do autor).

Por meio de autores como Rodrigo Otavio, portanto, o projeto de exaltação da terra gaúcha, de sua literatura e de sua gente, naquele contexto de forte otimismo da década de 1920, extrapolava as fronteiras do Rio Grande do Sul e chegava à capital do país, dotado de toda a credibilidade que o filho de um dos fundadores da Academia Brasileira de Letras poderia ter. $\mathrm{O}$ acesso a personalidades como Rodrigo Otavio Filho também não se dava de modo imediato, contudo: a intermediação que Rodrigo Otavio fazia entre a literatura de exaltação produzida no Rio Grande do Sul e a Capital Federal também dependia das relaçóes que ele estabelecera com um grupo particular de escritores gaúchos que havia se transferido para o Rio de Janeiro alguns anos antes. Na década de 1920, um grupo de jovens e promissores poetas gaúchos, que havia migrado para o Rio de Janeiro em 1909, àquela altura já plenamente inseridos nas rodas literárias cariocas, era o assim chamado "grupo da Praça 
da Misericórdia", de Porto Alegre, composto por sete intelectuais, dentre os quais quatro seguiram carreira no Rio de Janeiro: Álvaro Moreyra, Felipe d'Oliveira, Homero Prates, Antonius, Franciscus Barreto, Eduardo Guimaraens e Carlos de Azevedo.

Álvaro Moreyra, Felipe d'Oliveira, Homero Prates e o ilustrador Antonius uniram-se ao renomado grupo da Revista Fon-Fon!, na Capital Federal, que incluía o poeta simbolista Mario Pederneiras e Rodrigo Otavio Filho. É esse grupo de intelectuais vinculados à Fon-Fon!, constituído pelos quatro gaúchos, e por uma série de outros indivíduos oriundos de distintas partes do país, dentre eles o próprio Rodrigo Otavio Filho, que considero o centro articulador de importantes intermediaçóes entre as aspiraçóes políticas do Rio Grande do Sul daquele período, tanto no plano das ideias quanto no plano das açóes mais práticas, e os mundos da política do Rio de Janeiro. Assim, não é a revista em si, mas a confluência por ela propiciada, criando e recriando redes de relaçóes entre intelectuais das mais variadas procedências, que favorece $\mathrm{o}$ aparecimento de intelectuais mediadores, interessados na promoção de amigos e também de ideias que ultrapassam a esfera literária. No caso particular aqui estudado, foi a revista Fon-Fon! que possibilitou o vínculo entre Felipe d'Oliveira e Rodrigo Otavio Filho.

A partir de 1911, o grupo de gaúchos que já redigia na revista foi sendo apresentado à sociedade carioca em uma série de artigos intitulada $O$ momento literário. $\mathrm{O}$ artigo a respeito da vida e da obra de Felipe d'Oliveira, dizia o seguinte:

Felipe d'Oliveira é do Sul, como do Sul é o seu irmão siamês no Verso e na amizade, Alvaro Moreyra, o emotivo poeta original da Legenda da Luz e da Vida. Foi uma rajada do ar sadio dos pampas que soprou sobre a poesia dolorida dos nossos poetas daquela idade (MOMENTO LITERÁRIO, 1911, s.p., grifos do autor).

Já naquele momento, portanto, a literatura sulina era apontada como parte indissociável do locus onde se gestava, mesmo que os poetas em questão já não mais habitassem o solo do pampa há alguns anos. A literatura de Felipe d'Oliveira, contudo, mais do que fruto de "uma 
rajada do ar sadio dos pampas", era consequência do investimento de muitas geraçóes. Seu pai, Felipe Alves de Oliveira, pernambucano, sobre quem temos muito poucas informaçóes, foi membro do Partido Liberal, tendo sido enviado ao Rio Grande do Sul, ainda durante o Império, por intervenção do senador, líder máximo daquele partido, Gaspar Silveira Martins. Inicialmente na cidade de São Borja, na fronteira com a Argentina, Felipe fora mais tarde transferido para Santa Maria, na região central do estado, onde tornou-se primeiro delegado de polícia e, depois, Juiz Municipal, contraindo casamento com Adelaide Daudt, de família de origem germânica (DAUDT FILHO, 2003, p. 81).

É mais fácil obter informaçóes a respeito da família de Adelaide, sua mãe, uma vez que o irmão dela, João Daudt Filho, legou-nos um livro de memórias em que relata uma série de peculiaridades do clá dos Daudt que nos interessa compreender. Ele nos conta, por exemplo, que é com os primeiros imigrantes alemáes, em 1824, que seus antepassados chegam ao Rio Grande do Sul, mais especificamente para a cidade de Sáo Leopoldo. Somente no ano de 1835 transferiram-se para Santa Maria, onde igualmente havia um polo de colonização alemá. Por parte de mãe, os Daudt tinham parentesco com a família de Joaquim Francisco de Assis Brasil, um dos fundadores do Partido Republicano Rio-grandense (DAUDT FILHO, 2003, p. 21-23).

Além dos laços de sangue, João Daudt também informa-nos que sua família, particularmente sua mãe, preocupava-se em especial com as amizades que construiriam seus descendentes, sendo esse expediente muito importante na formação de vínculos com indivíduos importantes na política regional:

Quando muito menino, meus companheiros prediletos eram os 'moleques', subordinados a tudo quando eu queria, inclusive servirem de cavalos de minha montaria e puxadores do meu tosco carroção de duas rodas. Pouco a pouco, minha mãe me foi indicando melhor rumo; quando cheguei à adolescência, já não me aprazia essa camaradagem. Juntava-me, então, somente a rapazes de educação igual à minha e nesse meio, daí por diante, fui adquirindo os melhores amigos. Muitos destes se tornaram, mais tarde, homens de grande projeção social no parlamento, nos altos postos militares, 
na medicina, na engenharia, na indústria e no comércio (DAUDT FILHO, 2003, p. 25).

Seguindo os conselhos de sua mãe, João Daudt Filho, após passar por muitos estabelecimentos de ensino, na sua cidade natal e em outras, fez amizade com seletos companheiros. Sua circulação social, pela via da educação, foi extremamente importante para o estabelecimento de vínculos. Diante do falecimento do cunhado, assassinado em decorrência de uma série de intrigas políticas, João Daudt Filho prometeu buscar justiça e cuidar da família que o Juiz Felipe Alves de Oliveira deixava: seu filho pequeno João Daudt de Oliveira e o bebê que Adelaide ainda carregava no ventre, Felipe d'Oliveira (DAUD'T FILHO, 2003, p. 81-83).

Foi acompanhando a farmácia do tio que Felipe d'Oliveira transferiu-se para o Rio de Janeiro, em 1909. O estabelecimento que João Daudt Filho havia aberto no ano de 1882, em Santa Maria, por causa do enorme sucesso de seus produtos próprios, como a pomada Boro-Borácica e o xarope Bromil, buscava, na Capital Federal, maiores investimentos (DAUDT FILHO, 2003, p. 118123). Felipe era responsável pela seção de propaganda. Junto com ele, também seguiu para o Rio de Janeiro, no mesmo ano, Álvaro Moreyra (MOREYRA, 2007, p. 49).

No Rio de Janeiro, os poetas gaúchos fizeram novos amigos e acabaram por se inserir nas rodas literárias da capital do país. Álvaro Moreyra, em suas memórias, conta-nos assim como se deu esse processo:

Felippe D’Oliveira e eu chegamos ao Rio, nos fins de 1909. Eu trazia uma carta para Mário Pederneiras. Fomos, uma noite, visitá-lo, lá no largo do Humaitá, e ficamos logo da família. Conhecemos então Rodrigo Octavio Filho. Olegário Mariano também veio do mesmo tempo (MOREYRA, 2007, p. 49).

Com o sucesso da farmácia e com a boa inserção do grupo no Rio de Janeiro, seria natural esperar que o clá dos Daudt, em certo momento, julgasse oportuno também interferir na política. Em seu livro de memórias, João Daudt Filho coloca-se, em geral, como um narrador neutro em relação a diversos fatos políticos que acometeram 
o Rio Grande do Sul, inclusive aqueles que sucederam diretamente com a sua família. As relaçôes que mantinha, entretanto, eram extremamente personalizadas, muitas vezes recorrendo à lógica do favor, estabelecendo uma relação de dívida com outros indivíduos. Aliás, é João Neves da Fontoura quem relata o papel que a família Daudt, do poeta Felipe d'Oliveira, teve na composição da Aliança Liberal:

Mas nem João [refere-se a João Daudt de Oliveira, irmão mais velho de Felipe] nem Filipe se limitaram ao mundo material dos interesses. Filipe era um poeta, um escritor, um homem de sociedade, uma figura. João, sem ser um político, dispunha de um inesgotável espírito público. Rio-grandenses, com a paixão da terra natal, aqui se constituíram numa espécie de delegação permanente e desinteressada do Rio Grande, de seus homens, de suas possibilidades. Não importava o partido a que esses gaúchos pertencessem. O partido de João e Filipe era o Rio Grande, e, assim, tratavam de aproximar os conterrâneos, que chegavam, das personalidades de destaque, de fazê-los conhecidos, de dar-lhes oportunidades para o realce de seus dons. [...] Quando saltei do noturno de luxo, que me trouxe para o Rio, em 1928, eles lá estavam à espera. [...] Quando falar [...] sobre a formação do pacto de 1929, entre Minas e Rio Grande, ver-se-á o papel da estreita colaboração que os Daudt de Oliveira desempenharam no surto da Aliança Liberal (FONTOURA, 1958, p. 122).

De fato, João Neves da Fontoura ressalta que os irmãos João Daudt de Oliveira e Felipe d'Oliveira desempenharam grande papel na formação da Aliança Liberal, particularmente em razão das suas boas relaçôes, "desprendidas" de quaisquer amarras político-partidárias, tanto com políticos de carreira quanto com setores da imprensa. Ao que parece, as estratégias da família Daudt eram semelhantes àquelas de que se valia a geração anterior, com João Daudt Filho, o tio Jango. Joáo Daudt de Oliveira cursou a Faculdade de Direito de Porto Alegre, onde tornou-se amigo daquela que ficou conhecida como a "geração de 1907”, composta por João Neves da Fontoura, Maurício Cardoso, Getúlio Vargas e Firmino Paim. Seu envolvimento com política não 
se iniciou, entretanto, com a campanha pela formação da Aliança Liberal; antes disso, já havia participado do movimento da Reaçáo Republicana (1921-1922) pela candidatura de Nilo Peçanha em oposição a Artur Bernardes (DIAS, s.d.). Ainda segundo Fontoura,

A ligação principal de [Assis] Chateaubriand era com Felipe e João Daudt de Oliveira, dos quais anos antes se fizera amigo. Os irmáos Daudt de Oliveira dispunham aqui no Rio de sólida situação pessoal e social e ambicionavam ver um dos seus conterrâneos ascender à chefia do Governo da República.

Não sendo políticos no sentido confessional da palavra, não exercendo nem desejando cargos públicos, não dependendo dos Governos, a ação que desenvolviam para aquele fim, junto de seus amigos e da imprensa, se recomendava por indiscutível sinceridade.

Vargas, quando deputado federal e depois Ministro da Fazenda, aprofundara com ambos as relaçóes afetivas que datavam dos tempos de estudante em Porto Alegre, principalmente com João, pois Felipe pertencia a uma geração mais recente (FONTOURA, 1963, p. 52).

Provavelmente, João Neves da Fontoura exagerava quando dizia que nenhum interesse movia as ações dos dois irmãos, como se o empresariado em nada dependesse dos governos. Assim mesmo, o que nos interessa de seu registro é o fato de demarcar tanto a centralidade dos dois irmãos, um deles muito inserido no meio empresarial carioca, o outro, por sua vez, muito bem relacionado nas rodas literárias da mesma cidade, quanto por reiterar o papel fundamental dessas relaçóes na formação da Aliança Liberal.

No arquivo de Rodrigo Otavio Filho, na Fundação Casa de Rui Barbosa, encontramos uma série muito peculiar de registros documentais, ainda pouco explorados pelos historiadores: trata-se de convites para almoços e jantares em entidades como o Rotary e o Jockey Club, além de eventos organizados em grandes hotéis de luxo da Capital. Além do cardápio, tais convites em geral anunciam o objetivo do 
encontro (homenagem a algum indivíduo, apresen-tação de outro à sociedade etc.) e contam com as assinaturas de todos aqueles que dividiram a mesa durante o convescote (CARDÁPIO, 1918-1984).

Esses registros permitem entrever uma densa rede de relaçôes que unia escritores a políticos, empresários e a outros escritores. Se Rodrigo Otavio Filho, amigo íntimo de Felipe d'Oliveira, atuava na divulgação da nova produção literária do Rio Grande do Sul junto ao público da Capital Federal, ele também participava de reunióes sociais em homenagem a prefeitos e governadores, além de delegados oriundos do estrangeiro. Em seis de novembro de 1928, Rodrigo Otavio Filho esteve presente, por exemplo, ao evento em homenagem a João Neves da Fontoura, então deputado, no Jockey (CARDÁPIO, 06/11/1928). ${ }^{2}$ Talvez seja em ocasióes como essas em que o deputado gaúcho podia ser apresentado à sociedade carioca, tendo a oportunidade de fazer discursos, a que Fontoura se referia quando dizia que "[...] o novo líder parlamentar [referindo-se a si mesmo] do nosso estado náo encontrou amigos mais leais, conselheiros mais avisados, colaboradores mais eficientes. Muitos dos êxitos que conquistei naquele tempo, devo em parte a ambos [aos irmáos Daudt de Oliveira]" (FONTOURA, 1958, p. 122). Sem dúvida, a extensão de seus vínculos propiciava a mediação entre os gaúchos que recém-chegavam ao Rio com todo tipo de personalidade.

\section{Consideraçóes finais}

Seria precipitado afirmar que a Aliança Liberal foi articulada a partir das relaçóes mantidas pela família Daudt e por intelectuais como Rodrigo Otavio Filho, mas é preciso admitir que em parte isso é verdade, ao menos no que diz respeito a alguns dos primeiros movimentos nesse sentido. O papel mediador que a família teve, especialmente ao envolver outros agentes, seus amigos, nos múltiplos movimentos que criaram o clima propício para o sucesso político do golpe que levou Vargas ao poder em 1930, tem o potencial de advertir quanto a outros modos de participação política, não necessariamente vinculados, de modo direto, à política partidária, e também não necessariamente empreendidos pelos sujeitos clássicos da política 
nacional. A atuação da família Daudt teve múltiplas dimensões: Felipe d'Oliveira, juntamente com seu companheiro Rodrigo Otavio Filho, propiciou encontros entre os escritores gaúchos que escreviam, na década de 1920, sob clima de forte otimismo, levando suas ideias ao Rio de Janeiro; mas também tratou de inserir políticos de carreira, como o foi João Neves da Fontoura, nos meios de elite da Capital Federal, apresentando-os à sociedade do centro do país. Mediadores, Felipe e Rodrigo integraram, à sua maneira, a confluência de açôes que permitiram que as articulaçóes políticas ocorridas entre 1929 e 1930 conformassem não apenas um ajuste entre as ambiçôes políticas de inúmeros indivíduos e grupos envolvidos na Aliança Liberal, mas também o ambiente intelectual adequado à aceitação da ascensão de um presidente gaúcho naquele momento.

Além disso, o envolvimento de empresários como João Daudt de Oliveira nas articulaçóes do movimento de 30 permite vislumbrarmos o papel desses agentes, ligados à indústria e ao comércio, na política brasileira já na Primeira República, com uma participação de inegável proeminência. Tal participação, como se evidenciou no relato de João Neves da Fontoura, não se dava, naquele momento, por meio de discursos partidários, mas através de fórmulas abrangentes e em bastante consonância com o ambiente intelectual de Rio-grandizaçâo do Brasil estabelecido a partir da década de 1920: o partido de João e de Felipe era o Rio Grande. Sem dúvida, fórmulas como essa tinham, como ainda têm até hoje, o potencial de dar a impressão de que seus adeptos pairam acima das disputas mesquinhas que atravessam os partidos políticos, atendendo a interesses não de alguns grupos, mas de toda uma sociedade. No caso aqui estudado, essa sociedade era o estado do Rio Grande do Sul, que seria capaz, naquele momento, segundo o ponto de vista predominante no meio intelectual regional, de liderar uma renovação política em todo o Brasil, desmantelando os pactos entre oligarquias estaduais dominantes.

\section{THE RIO GRANDE'S PARTY: RELATIONSHIP NETWORKS, MEDIATION AND REVOLUTION OF 1930}

Abstract: The present article aims to analyze some of the forms of political participation in the articulations that formed the Aliança Liberal. At the center 
of the analysis, however, are not the classic agents in political history, such as career politicians and other individuals linked to party politics at the period, but intellectuals and, at the same time, businessmen. It is understood that these agents could have acted as mediators between politicians and prominent sectors of society, helping to establish an auspicious environment for the success of their endeavors. Keywords: Revolution of 1930. Intellectuals. Mediation.

\section{Notas}

${ }^{1}$ De acordo com Hélgio Trindade (1979), a política rio-grandense durante o período da Primeira República notabilizava-se pela divisão interna das oligarquias regionais, muito embora, a partir da década de 1920, tenha havido uma tendência a "um maior equilíbrio entre as forças políticas em luta" (p. 121).

${ }^{2}$ Antes disso, outros banquetes importantes envolveram Getúlio Vargas, quando de sua investidura no cargo de Ministro da Fazenda, em 1926, de cuja comissão de preparação Felipe d'Oliveira participou (CARDÁPIO, 20/11/1926); e Oswaldo Aranha, em 1927, em homenagem recebida de seus amigos e admiradores (CARDÁPIO, 01/10/1927).

\section{Referências}

BOURDIEU, Pierre. A economia das trocas simbólicas. São Paulo: Editora Perspectiva, 2005.

BROCA, José Brito. A Vida Literária no Brasil - 1900. Rio de Janeiro: J. Olympio, 1975.

CARDÁPIO - Rodrigo Otavio Filho. Rio de Janeiro; Poços de Caldas; São Paulo: [s.n.], de 29 jun. 1918 a 22 set. 1984. 183 docs, Impresso. Arquivo da Fundação Casa de Rui Barbosa. ROf. Dv.

. Rio de Janeiro: [s.n.], 20/11/1926. Impresso. Arquivo da Fundação Casa de Rui Barbosa. ROf. Dv.

. Rio de Janeiro (BR): [s.n.], 01/10/1927. Impresso. Arquivo da Fundação Casa de Rui Barbosa. ROf. Dv.

. Rodrigo Otavio Filho. Rio de Janeiro: [s.n.], 06/11/1928. Impresso. Arquivo da Fundação Casa de Rui Barbosa. ROf. Dv.

DAUDT FILHO, João. Memórias. Santa Maria: Editora UFSM, 2003.

Anos 90, Porto Alegre, v. 23, n. 43, p. 179-197, jul. 2016 
DIAS, Sônia. João Daudt d'Oliveira. Dicionário da Elite Política Republicana (1889-1930). CPDOC, FGV. Disponível em: http://cpdoc.fgv.br/sites/default/ files/verbetes/primeira-republica/OLIVEIRA,\%20Jo\%C3\%A3o\%20Daudt\%20d'. pdf. Acesso em: 15 dez. 2015.

FILHO, Rodrigo Otavio. Na terra do chimarrão... 1928 (trecho de um passeio). Arquivo da Fundação Casa de Rui Barbosa. Documento textual de arquivo. ROf Pi., 1928.

FONTOURA, João Neves da. Memórias: Borges de Medeiros e seu tempo. Porto Alegre: Editora Globo, 1958.

. Memórias: A Aliança Liberal e a Revolução de 1930. Porto Alegre: Editora Globo, 1963.

HALLEWELL, Laurence. O livro no Brasil (sua história). São Paulo: Editora da Universidade de São Paulo, 1985.

LEITE, Ligia Chiappini Moraes Leite. Regionalismo e modernismo. São Paulo: Editora Ática, 1978.

LEVI, Giovanni. A herança imaterial: a trajetória de um exorcista no Piemonte do século XVII. Rio de Janeiro: Civilização Brasileira, 2000.

MAYA, Alcides. Através da imprensa. Porto Alegre: Octaviano Borba \& Irmão, 1900.

MICELI, Sérgio. Intelectuais à brasieira. São Paulo: Companhia das Letras, 2001. MOMENTO LITERÁRIO. Fon-Fon! Rio de Janeiro, 7 out. 1911.

MOREYRA, Álvaro. As amargas, não. Rio de Janeiro: Academia de Letras, 2007. MURARI, Luciana. "Água parada": o olhar da modernidade na ficção de Alcides Maya. Estudos Ibero-americanos, PUCRS, v. XXXIV, n.2, p. 150-167, dez. 2008. . A construção da identidade social na literatura regionalista: o caso sul-rio-grandense. Anos 90, Porto Alegre, v. 17, n. 32, p. 159-183, dez. 2010.

O DIA. Petit Journal. Porto Alegre, 05 dez. 1906.

SIRINELLI, Jean-François. Os intelectuais. In: RÉMOND, René (Org.). Por uma história política. Rio de Janeiro: Editora FGV, 2003.

TRINDADE, Hélgio. Aspectos políticos do sistema partidário republicano riograndense (1882-1937): da confrontação autoritário-liberal à implosão da aliança político-revolucionária de 30. In: DACANAL, José Hildebrando; GONZAGA, Sergius (Org.). RS: economia \& política. Porto Alegre: Mercado Aberto, 1979. p. 119-191. 
VERGARA, Pedro. Mansueto Bernardi: esboço de uma grande vida. Rio de Janeiro: IBGE, 1960.

WOLF, Eric. Aspectos das relaçôes de grupos em uma sociedade complexa: México. In: FELDMAN-BIANCO, Bela; RIBEIRO, Gustavo Lins. Antropologia e poder: contribuiçóes de Eric R. Wolf. São Paulo: Editora Universidade de Brasília; Imprensa Oficial do Estado de Sáo Paulo. Universidade Estadual de Campinas, 2003.

Recebido em: 15/ 12/ 2015 Aprovado em: 22/ 03/ 2016 